\title{
Perioperative dexmedetomidine reduces delirium in elderly patients after non-cardiac surgery: a systematic review and meta- analysis of randomized-controlled trials

\author{
La dexmédétomidine périopératoire réduit le delirium chez les \\ patients âgés après une chirurgie non cardiaque: revue \\ systématique et méta-analyse d'études randomisées contrôlées
}

\author{
Hao Pan, MD • Chengxiao Liu, PhD • Xiaochun Ma, PhD • Yanbing Xu, PhD • \\ Mengyuan Zhang, PhD • Yan Wang, PhD
}

Received: 29 January 2019/Revised: 29 April 2019/Accepted: 3 May 2019/Published online: 1 July 2019

(C) Canadian Anesthesiologists' Society 2019

\begin{abstract}
Background Delirium is a frequent postoperative complication in elderly patients after non-cardiac surgery. We performed this updated meta-analysis to ascertain more precisely the efficacy of dexmedetomidine $(D E X)$ on the incidence of postoperative delirium (POD) in elderly patients after non-cardiac surgery.

Methods We searched PubMed, EMBASE, the Cochrane Library, Web of Science, and the Cumulative Index of Nursing and Allied Health Literature (CINAHL) from inception until February 24, 2019. In this meta-analysis, we included randomized-controlled trials comparing the effect of DEX vs normal saline (NS) or other anesthetic drugs on $P O D$ incidence in elderly (either $\geq 60$ or $\geq 65 \mathrm{yr}$ old) patients undergoing non-cardiac surgery. We performed subgroup analyses of the DEX dosing strategy (starting time, dose, and duration of administration, with or without loading dose) and the strategy of various control drugs. A random-effects model was used for all analyses.

Results We included 11 studies involving 2,890 patients in our meta-analysis. The pooled results of these studies revealed that DEX significantly reduced the incidence of $P O D$ (relative risk [RR], 0.47; 95\% confidence interval [CI], 0.38 to 0.58; $P<0.001)$ compared with the control group. Meanwhile, the incidences of hypotension (RR,
\end{abstract}

H. Pan, MD - C. Liu, PhD - X. Ma, PhD - Y. Xu, PhD .

M. Zhang, PhD · Y. Wang, PhD ( $)$

Department of Anesthesiology, Shandong Provincial Hospital

Affiliated to Shandong University, No. 324 Jingwu Road, Jinan

250021, China

e-mail: wangyan20080826@163.com
1.20; $95 \%$ CI, 1.04 to $1.39 ; P=0.01)$ and bradycardia (RR, 1.33; 95\% CI, 1.08 to $1.63 ; P=0.007)$ were increased in the DEX group. Subgroup analyses revealed a decrease in POD incidence when DEX was administered intraoperatively $(R R, 0.43 ; 95 \% C I, 0.33$ to $0.57 ; P<$ $0.001)$ and postoperatively (RR, 0.38; $95 \% \mathrm{CI}, 0.27$ to $0.54 ; P<0.001)$ with a loading dose (RR, 0.49; 95\% CI, 0.36 to $0.69 ; P<0.001)$ compared with NS (RR, 0.49; $95 \%$ $C I, 0.37$ to $0.64 ; P<0.001)$ and other anesthetic drugs (RR, 0.40; 95\% CI, 0.26 to 0.60; $P<0.001$ ). There were significant differences in the time to extubation (standardized mean difference, -0.60; 95\% CI, -1.17 to 0.03; $P=0.04$ ) and the length of hospital stay (mean difference, -0.50 days; $95 \%$ CI, -0.97 to $-0.03 ; P=0.04$ ). The amount of data for the duration of mechanical ventilation and length of intensive care unit stay were insufficient to perform a meta-analysis.

Conclusion Perioperative dexmedetomidine reduces the incidence of POD in elderly patients after non-cardiac surgery, but this comes at the cost of an increased incidence of hypotension and bradycardia.

\section{Résumé}

Contexte Le delirium est une complication postopératoire fréquente chez les patients âgés après une chirurgie non cardiaque. Nous avons réalisé cette méta-analyse mise à jour pour déterminer de façon plus précise l'efficacité de la dexmédétomidine (DEX) sur l'incidence de delirium postopératoire (DPO) chez les patients âgés après une chirurgie non cardiaque.

Méthode Nous avons effectué des recherches dans les bases de données PubMed, EMBASE, Cochrane Library, 
Web of Science et dans le Cumulative Index of Nursing and Allied Health Literature depuis leur création et jusqu'au 24 février 2019. Dans cette méta-analyse, nous avons inclus les études randomisées contrôlées comparant l'effet de la DEX vs une solution physiologique salée (NS) ou d'autres médicaments anesthésiques sur l'incidence de DPO chez les patients âgés (soit $\geq 60$ ou $\geq 65$ ans) subissant une chirurgie non cardiaque. Nous avons réalisé des analyses de sous-groupes du régime posologique de la DEX (moment d'amorce, dose et durée de l'administration, avec ou sans dose de charge) et de la stratégie des divers médicaments témoin. Un modèle à effets aléatoires a été utilisé pour toutes les analyses.

Résultats Nous avons inclus 11 études portant sur 2890 patients dans notre méta-analyse. Les résultats pondérés de ces études ont révélé que la DEX réduisait significativement l'incidence de DPO (risque relatif [RR], 0,47; intervalle de confiance [IC] $95 \%, 0,38$ à 0,58; $P<0,001)$ par rapport au groupe témoin. En revanche, les incidences d'hypotension (RR, 1,20; IC $95 \%, 1,04$ à 1,39; $P=0,01)$ et de bradycardie (RR, 1,33; IC $95 \%, 1,08$ à 1,63; $P=0,007)$ étaient plus élevées dans le groupe DEX. Les analyses de sous-groupe ont révélé une réduction de l'incidence de DPO lorsque la $D E X$ était administrée en période peropératoire $(R R, 0,43$; IC $95 \%, 0,33$ à 0,57; $P<0,001)$ et postopératoire ( $R R, 0.38$; IC $95 \%, 0,27$ à 0,54; $P<0,001)$ avec une dose de charge ( $R R, 0,49 ;$ IC $95 \%, 0,36$ à 0,69; $P<0,001)$ par rapport à la NS (RR, 0,49; IC $95 \%, 0,37$ à 0,64; $P<0,001)$ et aux autres médicaments anesthésiques (RR, 0,40; IC $95 \%, 0,26$ à 0,60; $P<0,001)$. Des différences significatives ont été observées dans le temps pour l'extubation (différence moyenne standardisée, -0,60; IC 95\%, -1,17 à -0,03; P = 0,04) et la durée de séjour à l'hôpital (différence moyenne, -0,50 jour; IC 95 \%, -0,97 à -0,03; P=0,04). La quantité de données concernant la durée de la ventilation mécanique et la durée de séjour à l'unité de soins intensifs était insuffisante pour réaliser une méta-analyse.

Conclusion La dexmédétomidine périopératoire réduit l'incidence de DPO chez les patients âgés après une chirurgie non cardiaque, mais cette réduction vient au coût d'une incidence accrue d'hypotension et de bradycardie.

Delirium, which is an acute disorder of cognition, attention, and perception, is a common, serious, and often potentially preventable clinical syndrome with an increased risk of morbidity and mortality among patients who are $65 \mathrm{yr}$ of age or older. ${ }^{1,2}$ The prevalence of delirium ranges from 12 to $51 \%$ in patients after non-cardiac surgery, and it increases with age. ${ }^{2,3}$ Postoperative delirium (POD) is distressing for patients and their families, and has been associated with higher morbidity and mortality, prolonged length of hospital stay, and increased healthcare costs. ${ }^{4}$ At present, primary prevention with multicomponent nonpharmacological approaches has gained widespread acceptance as the most effective strategy for delirium. ${ }^{2,5}$ These approaches include reorientation, therapeutic activities, reduction of psychoactive medications, early mobilization, promoting sleep, maintaining hydration and nutrition, and providing vision and hearing adaptations. Dexmedetomidine (DEX) is a highly selective alpha- $2\left(\alpha_{2}\right)$ adrenoreceptor agonist that provides anxiolysis, sedation, and modest analgesia with minimal respiratory depression. ${ }^{6}$ One randomizedcontrolled trial (RCT) and one meta-analysis have shown that DEX reduces the incidence of POD in patients after cardiac surgery. ${ }^{7,8}$ Recently, another RCT revealed that DEX was associated with a decrease in POD incidence in elderly patients undergoing non-cardiac surgery. ${ }^{3}$ Nevertheless, the literature is not entirely congruent, with another study concluding that DEX does not decrease the incidence of delirium in elderly patients after non-cardiac surgery. ${ }^{9}$ A recent meta-analysis of RCTs by Duan et al. ${ }^{10}$ revealed that DEX reduced the incidence of POD in elderly patients after both cardiac and non-cardiac surgery. A recent meta-analysis assessed the effect of DEX on the incidence of delirium in the intensive care unit (ICU) and concluded that DEX might be more efficacious than placebo or standard sedatives in reducing POD in patients after cardiac and noncardiac surgery. ${ }^{11}$ Nevertheless, this meta-analysis did not include some published non-English studies, and, in the meantime, a number of more recent studies evaluating the effect of DEX on delirium in elderly patients after noncardiac surgery have been published. Therefore, we performed an updated meta-analysis of RCTs to ascertain more precisely the efficacy of DEX on POD incidence in elderly patients after non-cardiac surgery.

\section{Methods}

This meta-analysis was reported according to the Preferred Reporting Items for Systematic Reviews and MetaAnalyses statement. ${ }^{12}$

Search strategy

We systematically searched relevant articles via PubMed, EMBASE, the Cochrane Library, Web of Science, and the Cumulative Index of Nursing and Allied Health Literature (CINAHL) from inception to February 24, 2019. We retrieved conference proceedings from Conference Proceedings Citation Index-Science (CPCI-S) and CPCI-Social Science \& Humanities (CPCI-SSH). In addition, we searched ClinicalTrials.gov and grey-literature databases (GreyNet International, OpenGrey, and System for Information on 
Grey Literature in Europe) to identify further eligible studies. Finally, we manually searched the references of our included studies and of previous systematic reviews for further studies that were not identified in our initial search. A senior specialist in evidence-based medicine reviewed the final search result. Our basic search strategy included the following terms: ("dexmedetomidine" [MeSH Terms] OR "dexmedetomidine"[All Fields]) AND ("delirium"[MeSH Terms] OR "delirium"[All Fields]) AND ("aged" [MeSH Terms] OR “aged"[All Fields] OR "elderly"[All Fields]). No language restrictions were applied to the search.

\section{Eligibility criteria}

We included studies with the following criteria: 1) subjects were elderly patients (either $\geq 60$ or $\geq 65$ yr old) undergoing non-cardiac surgery; 2) the study compared the effect of DEX with that of normal saline (NS) or other anesthetic drugs, regardless of starting time, dose, or duration of administration; 3) incidence of POD was reported as the outcome; 4) studies were RCTs; 5) the Confusion Assessment Method (CAM) or CAM-ICU was used to evaluate delirium; and 6) the full text was available.

\section{Exclusion criteria}

Non-RCTs, case reports, conference abstracts, comments, and systematic reviews were excluded. Studies involving cardiac surgery, non-elderly patients, the combination regimes of DEX and other drugs, oral DEX, and animal experiments were also excluded.

\section{Study selection and data collection process}

Two authors (P.H. and Z.M.Y.) independently performed the eligible study selection and data extraction. Disagreements between these two authors were resolved by discussion with a third author (W.Y.). The extracted data were as follows: first author; year of publication; age; surgery type; number of patients; starting time; dose and duration of DEX; anesthesia depth monitoring; and methods of delirium assessment. Although the primary endpoint was the incidence of delirium, secondary outcomes were also extracted including hypotension, bradycardia, time to extubation, duration of mechanical ventilation (MV), and length of ICU and hospital stays. Hypotension and bradycardia were defined by the authors of individual studies.

Risk of bias in individual studies

We used the Cochrane Collaboration tool for assessing the risk of bias (Cochrane, London, UK) to evaluate the quality of included studies. ${ }^{13}$ This assessment was completed independently by two authors (P.H. and Z.M.Y.); disagreements were resolved by discussion with a third author (W.Y.) until a consensus was reached.

\section{Statistical analysis}

We performed the meta-analyses using Review Manager software version 5.3 (Cochrane). Risk ratios (RR) and their 95\% confidence intervals (CI) were calculated for dichotomous outcomes. For continuous outcomes, mean differences (MD) or standardized mean differences (SMD) with $95 \%$ CIs were calculated. When median and interquartile range or median and $95 \%$ CI were used in included studies, standard deviation was calculated by the formula suggested by the Cochrane Handbook. A randomeffects model using the DerSimonian and Laird method was applied in all analyses. Statistical heterogeneity was assessed by the Chi square test and $\mathrm{I}^{2}$ index (where we considered an $\mathrm{I}^{2}>50 \%$ to represent substantial heterogeneity).

Subgroup analyses of various DEX strategies (starting time, dose and duration of administration, with or without loading dose) were performed to evaluate the efficacy of these strategies on POD. We also performed subgroup analysis of the strategy for various control drugs to evaluate the effect of DEX on POD and explore any potential source of heterogeneity. We also performed a sensitivity analysis to evaluate the stability of the pooled results. To evaluate potential publication bias, we created a funnel plot, and we assessed its symmetry using Egger's test using Stata version 15 (StataCorp LLC, College Station, TX, US). $P<0.05$ (two-sided) was considered to be statistically significant.

\section{Results}

Study selection

A flow chart of study selection is shown in Fig. 1. We initially identified 988 studies by searching databases and references. After screening these articles according to titles and abstracts, we excluded 962 that did not meet eligibility criteria. In total, we preliminarily evaluated 26 full-text articles for eligibility. Ultimately, we included 11 studies $^{3,9,14-22}$ meeting all eligibility criteria in our meta-analysis.

Study characteristics

Characteristics of the included studies and DEX strategies are presented in Tables 1 and 2, respectively. We acquired POD incidence data from one study ${ }^{21}$ using Getdata Graph 


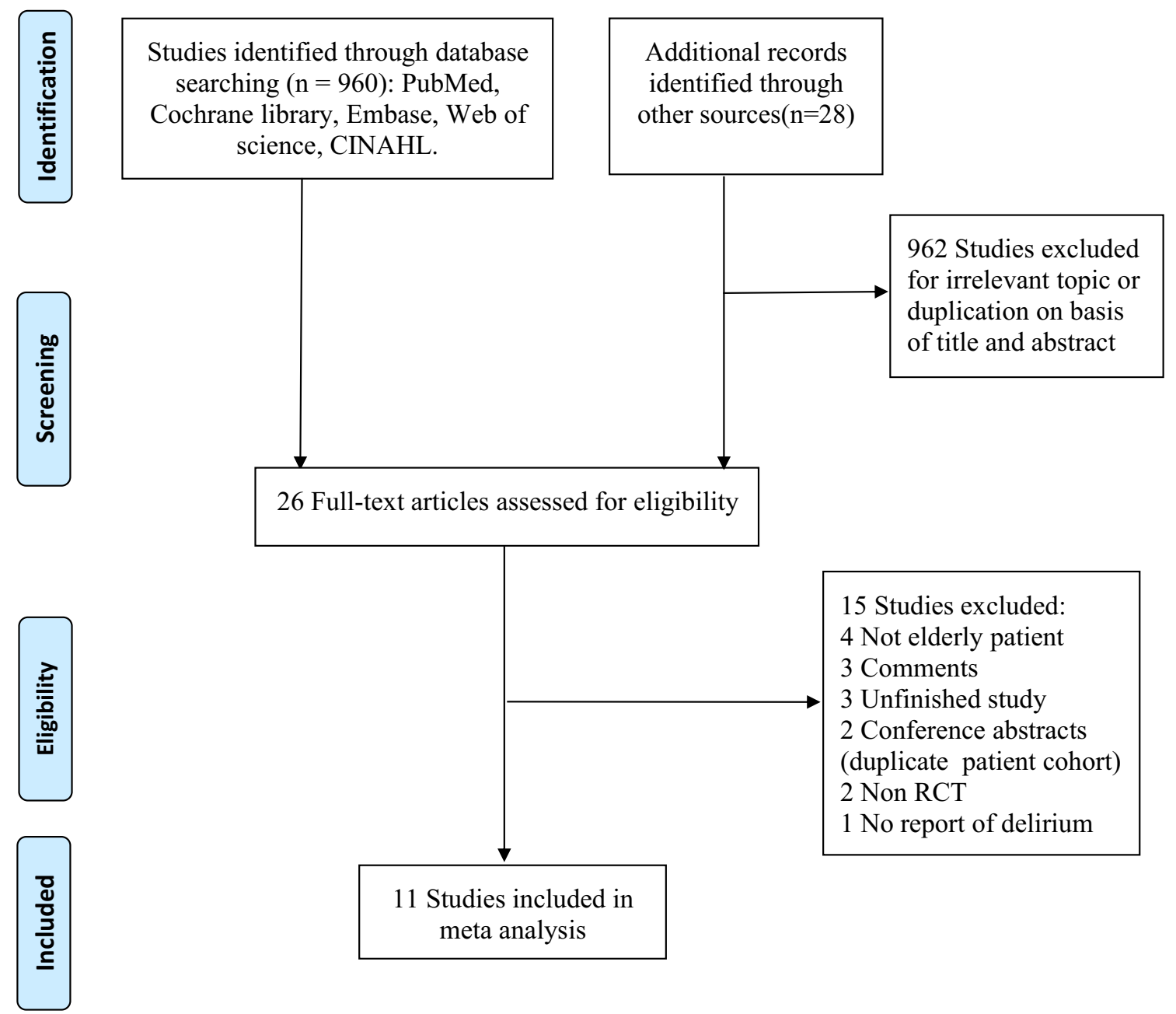

Fig. 1 Flow chart of study selection

Digitizer software (http://getdata-graph-digitizer.com/). Dexmedetomidine starting time and dose varied across the included studies. Patients in four studies ${ }^{3,15,16,22}$ received DEX during the postoperative period, but those in the study by Deiner $e t a l .{ }^{9}$ received DEX during the intraoperative period and two subsequent hours. In six other studies, ${ }^{14,17-21}$ DEX was administered during the intraoperative period only. In four studies, the loading doses used were $1.0 \mu \mathrm{g} \cdot \mathrm{kg}^{-1},{ }^{14,20} 0.8-1.0 \mu \mathrm{g} \cdot \mathrm{kg}^{-1},{ }^{19}$ and $0.5 \mu \mathrm{g} \cdot \mathrm{kg}^{-1},{ }^{21}$ but in other studies DEX was administered continuously at different rates $\left(0.1-0.7 \mu \mathrm{g} \cdot \mathrm{kg}^{-1} \cdot \mathrm{hr}^{-1}\right)$ without a loading dose. ${ }^{3,9,15-18,22}$ In five studies, ${ }^{14,15,18,19,21}$ different anesthetic drugs (propofol, midazolam, or ketamine) were used in the control group, whereas eight studies ${ }^{3,9,14,16,17,20-22}$ used NS in the control group. These studies differed in duration of DEX administration. Nevertheless, only two studies $^{3,16}$ reported the exact data of duration $-12 \mathrm{hr}^{16}$ and $14.95 \mathrm{hr}^{3}$ Although one study ${ }^{9}$ also reported duration of DEX administration (two hours) during the postoperative period, the figure for the intraoperative period was not obtainable. The total mean (standard deviation) dose of DEX was 105 (43) $\mu \mathrm{g}$ in one study, ${ }^{19}$ but the exact amount of DEX administered was not reported in the other studies. The largest study included 700 patients, ${ }^{3}$ while the smallest had 90 patients. ${ }^{14,21}$

Risk of bias within studies

The results of quality assessment are presented in Fig. 2 . One study ${ }^{20}$ was rated as high risk for "blinding of participants and personnel" bias, while another ${ }^{22}$ was rated as high risk for "selective reporting" bias.

\section{Meta-analysis of POD}

This meta-analysis of 11 studies including 2,890 patients showed that DEX was associated with a significant decrease in the incidence of POD (RR, $0.47 ; 95 \% \mathrm{CI}$, 0.38 to $0.58 ; P<0.001$; Fig. 3$)$. Heterogeneity $\left(\mathrm{I}^{2}=26 \%\right.$; $P=0.20$ ) between included studies was not substantial. We 


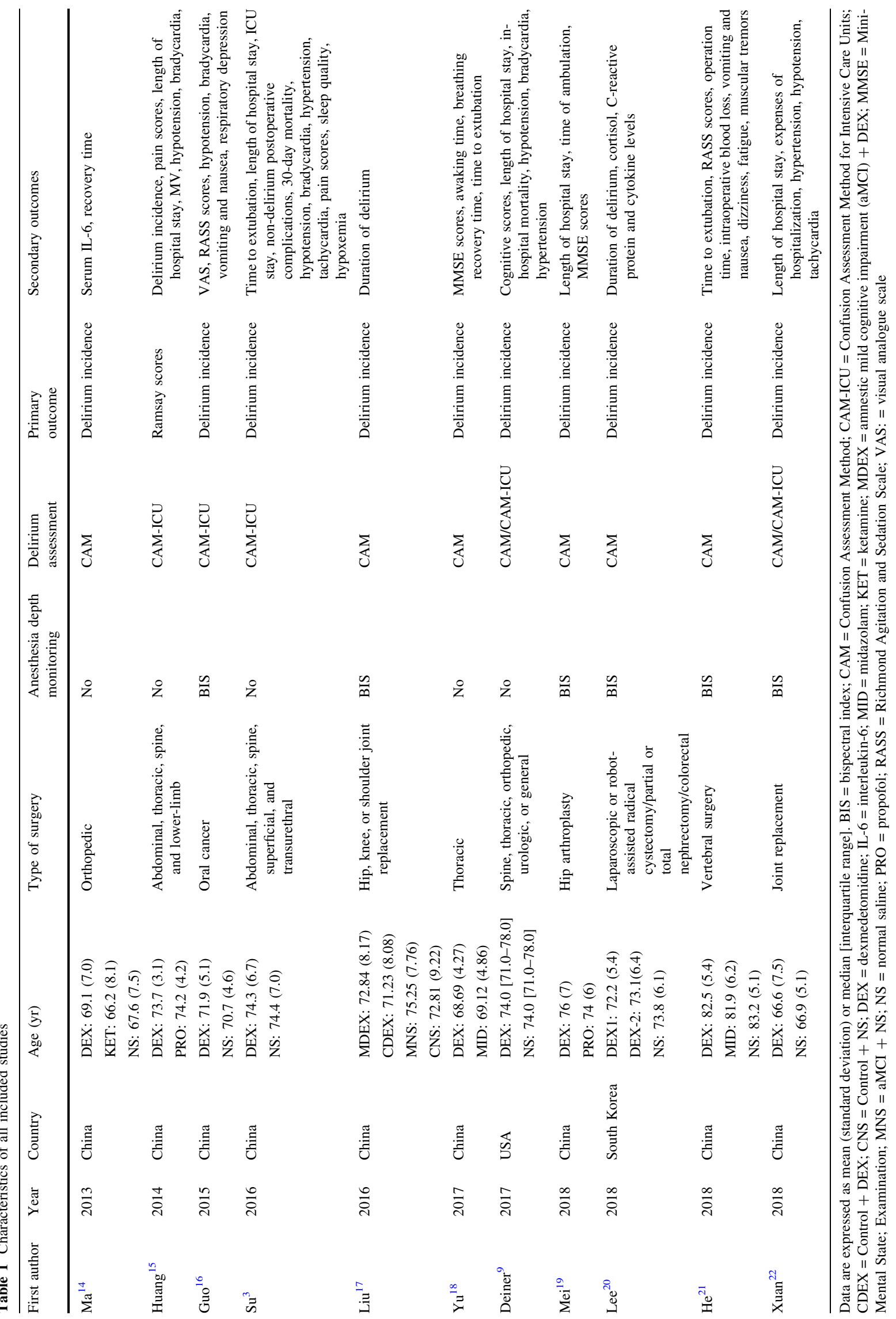


Table 2 DEX strategy

\begin{tabular}{|c|c|c|c|c|c|c|}
\hline \multirow[t]{2}{*}{ Studies } & \multicolumn{2}{|c|}{ No. of patients in study } & \multicolumn{2}{|l|}{ DEX dose } & \multirow[t]{2}{*}{ Starting time and duration of DEX } & \multirow[t]{2}{*}{ Control } \\
\hline & DEX & Control & Loading dose & $\begin{array}{l}\text { Infusion rate } \\
\left(\mu \mathrm{g} \cdot \mathrm{kg}^{-1} \cdot \mathrm{hr}^{-1}\right)\end{array}$ & & \\
\hline $\mathrm{Ma}^{14}$ & 30 & $\begin{array}{l}\text { KET: } 30 \\
\text { NS: } 30\end{array}$ & $1.0 \mu \mathrm{g} \cdot \mathrm{kg}^{-1}$ for $10 \mathrm{~min}$ & 0.5 & $\begin{array}{l}\text { Started } 10 \text { min before induction; maintained until } \\
30 \text { min before end of surgery }\end{array}$ & $\begin{array}{r}\text { KET, } \\
\text { NS }\end{array}$ \\
\hline Huang $^{15}$ & 54 & 54 & N/A & $0.2-0.7$ & $\begin{array}{l}\text { Started immediately after arrival in ICU; } \\
\text { maintained during MV }\end{array}$ & PRO \\
\hline $\mathrm{Guo}^{16}$ & 78 & 78 & N/A & 0.2 & $\begin{array}{l}\text { Started immediately after arrival in SICU; } \\
\text { maintained for } 12 \mathrm{~h}\end{array}$ & NS \\
\hline $\mathrm{Su}^{3}$ & 350 & 350 & N/A & 0.1 & $\begin{array}{l}\text { Start within } 1 \mathrm{~h} \text { after arrival in ICU; maintained } \\
\text { until 8:00 a.m. on 1st day after surgery }\end{array}$ & NS \\
\hline $\mathrm{Liu}^{17}$ & 99 & 98 & N/A & $0.2-0.4$ & $\begin{array}{l}\text { Infusion during surgery; stopped } 20 \text { min before end } \\
\text { of surgery }\end{array}$ & NS \\
\hline $\mathrm{Yu}^{18}$ & 46 & 46 & N/A & $0.2-0.7$ & $\begin{array}{l}\text { Infusion during surgery; stopped at the end of } \\
\text { surgery }\end{array}$ & MID \\
\hline Deiner $^{9}$ & 189 & 201 & N/A & 0.5 & $\begin{array}{l}\text { Started on entering operating room; maintained } \\
\text { until } 2 \mathrm{~h} \text { into recovery }\end{array}$ & NS \\
\hline $\mathrm{Mei}^{19}$ & 148 & 148 & $0.8-1.0 \mu \mathrm{g} \cdot \mathrm{kg}^{-1}$ & $0.1-0.5$ & $\begin{array}{l}\text { Started with loading dose over } 15-20 \mathrm{~min} \\
\text { maintained until end of surgery }\end{array}$ & PRO \\
\hline $\mathrm{Lee}^{20}$ & $\begin{array}{l}\text { Group 1: } 95 \\
\text { Group 2: } 114\end{array}$ & 109 & $\begin{array}{l}\text { Group 1: } 1.0 \mu \mathrm{g} \cdot \mathrm{kg}^{-1} \\
\text { Group 2: } 1.0 \mu \mathrm{g} \cdot \mathrm{kg}^{-1}\end{array}$ & $\begin{array}{l}\text { Group 1: } 0.2-0.7 \\
\text { Group 2: N/A }\end{array}$ & $\begin{array}{l}\text { Group 1: started from induction; maintained until } \\
\text { end of surgery } \\
\text { Group 2: bolus at } 15 \text { min before the end of surgery } \\
\text { over } 10 \text { min }\end{array}$ & NS \\
\hline $\mathrm{He}^{21}$ & 30 & $\begin{array}{l}\text { MID: } 30 \\
\text { NS: } 30\end{array}$ & $0.5 \mu \mathrm{g} \cdot \mathrm{kg}^{-1}$ & 0.4 & $\begin{array}{l}\text { Started } 10 \text { min before induction; maintained until } \\
\text { end of surgery }\end{array}$ & $\begin{array}{l}\text { MID, } \\
\text { NS }\end{array}$ \\
\hline Xuan $^{22}$ & 227 & 226 & N/A & 0.1 & $\begin{array}{l}\text { Started within } 1 \mathrm{~h} \text { after arrival in ICU; maintained } \\
\text { for } 3 \text { days }\end{array}$ & NS \\
\hline
\end{tabular}

DEX = dexmedetomidine; ICU = intensive care unit; KET = ketamine; MID = midazolam; MV = mechanical ventilation; NS = normal saline; $\mathrm{PRO}=$ propofol; $\mathrm{SICU}=$ surgical intensive care unit

next performed a sensitivity analysis of POD incidence by excluding each study individually. Exclusion of the study by Mei et al., ${ }^{19}$ in which patients received regional anesthesia resulted in a similar pooled result (RR, 0.47; 95\% CI, 0.37 to $0.60 ; P<0.001)$. Statistical heterogeneity $\left(\mathrm{I}^{2}=0 \% ; P=0.92\right)$ was absent when the study conducted by Deiner et $a l .{ }^{9}$ was excluded, but the pooled result changed minimally (RR, $0.43 ; 95 \% \mathrm{CI}, 0.36$ to $0.52 ; P<$ 0.001). To limit the risk of bias, we performed a sensitivity analysis excluding the two studies with a high risk of bias. $^{20,22}$ The result (RR, $0.45 ; 95 \%$ CI, 0.33 to $0.60 ; P<$ $0.001 ; \mathrm{I}^{2}=36 \%$ ) was consistent with that of primary analysis for all studies. When we conducted another sensitivity analysis excluding the studies that did not monitor anesthesia depth by bispectral index (BIS), the pooled results remained similar (RR, $0.44 ; 95 \% \mathrm{CI}, 0.36$ to $0.55 ; P<0.001)$, and statistical heterogeneity was absent $\left(\mathrm{I}^{2}=0 \% ; P=0.66\right)$.

We conducted a subgroup analysis based on starting time of DEX administration (intraoperative, postoperative, or perioperative; Fig. 4). We grouped four studies ${ }^{3,15,16,22}$ including 1,417 patients into the postoperative period subgroup and six studies ${ }^{14,17-21}$ including 1,083 patients into the intraoperative period subgroup. The test of subgroup differences showed a statistically significant subgroup effect $(P$ for interaction $=0.008)$, meaning that starting time of administration modified the effect of DEX on POD incidence compared with control. Pooled results showed that a decrease of POD incidence favoured DEX over control drugs during the intraoperative (RR, 0.44; 95\% CI, 0.34 to $0.58 ; P<0.001 ; \mathrm{I}^{2}=0 \%$ ) and postoperative periods (RR, $0.42 ; 95 \% \mathrm{CI}, 0.32$ to $0.54 ; P$ $\left.<0.001 ; \mathrm{I}^{2}=0 \%\right)$. Nevertheless, we included only one study $^{9}$ in the perioperative (intraoperative and postoperative) period subgroup, so this result might be uncertain and required further confirmation.

We conducted another subgroup analysis by whether a loading dose was used (Fig. 5). In four studies, ${ }^{14,19-21}$ patients (combined total of 794 patients) received DEX with a loading dose; in the other seven studies, $3,9,15-18,22$ 


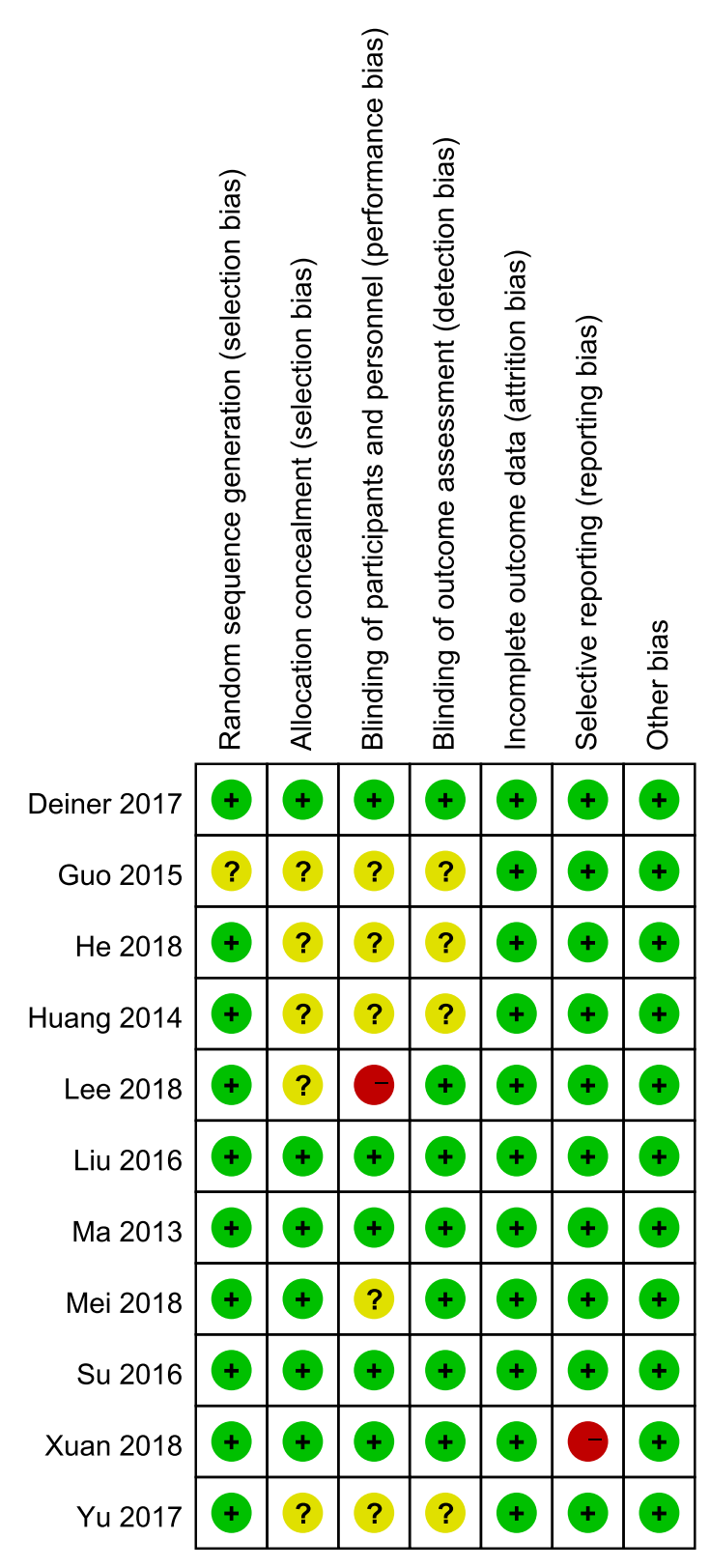

Fig. 2 Risk of bias assessment according to the Cochrane Risk of Bias Methods

(combined total of 2,096 patients) there was no loading dose. The test of subgroup differences indicated no statistically significant subgroup effect $(P$ for interaction $=0.67$ ), suggesting that administration of DEX with or without loading dose did not modify the effect of DEX on POD incidence in comparison with controls. Nevertheless, the DEX-with-loading-dose subgroup comprised only a small number of trials and patients. So this analysis might be underpowered to detect subgroup differences. Pooled subgroup results revealed that POD incidence decreased in the DEX-with-loading-dose subgroup (RR, 0.50; 95\% CI, 0.36 to $\left.0.70 ; P<0.001 ; \mathrm{I}^{2}=0 \%\right)$. Nevertheless, there was significant heterogeneity between the studies included in the DEX-without-loading-dose subgroup $\left(\mathrm{I}^{2}=52 \%\right)$. There was no certain evidence to confidently confirm this result of the subgroup effect so that further explanation for the heterogeneity was needed.

We performed further subgroup analysis for different control drugs (NS, propofol, midazolam, or ketamine; Fig.6). Two studies ${ }^{14,21}$ included two comparators in addition to DEX (groups 1 and 2). Eight studies with 2,334 patients contributed data to the NS subgroup, and five studies with 616 patients contributed to the anesthetic drug subgroup. The test for subgroup differences suggested that there was no statistically significant subgroup effect $(P$ for interaction $=0.41$ ), meaning that different control drugs did not modify the effect of DEX on POD compared with controls. Nevertheless, a smaller number of trials and patients contributed data to the anesthetic drug subgroup compared with the NS subgroup. This means that the analysis may be underpowered to detect subgroup differences. The results suggested that DEX could significantly reduce POD incidence in the anesthetic drug subgroup (RR, $0.40 ; 95 \% \mathrm{CI}, 0.26$ to $0.60 ; \mathrm{I}^{2}=0 \%$ ), but there was a mild statistical heterogeneity in the NS subgroup $\left(\mathrm{I}^{2}=45 \%\right)$. Therefore, there was no certain evidence to confidently confirm this result of the subgroup effect.

\section{Meta-analysis of secondary outcomes}

The incidence of hypotension was reported in five studies, $3,9,15,16,22$ while that of bradycardia was reported in four studies. ${ }^{3,9,15,16}$ These studies all defined hypotension and bradycardia differently; the definitions are summarized in Table 3 . There was a significant increase in the incidences of hypotension (RR, 1.20; $95 \%$ CI, 1.04 to $1.39 ; P=0.01 ; \mathrm{I}^{2}=0 \%$ ) and bradycardia (RR, $1.33 ; 95 \%$ CI, 1.08 to $1.63 ; P=0.007 ; \mathrm{I}^{2}=0 \%$ ) in the DEX group compared with the control groups. Three studies $^{3,18,21}$ compared the time to extubation between the two groups. Our meta-analysis showed that DEX could significantly shorten the time to extubation (SMD, -0.60; $95 \% \mathrm{CI},-1.17$ to $-0.03 ; P=0.04 ; \mathrm{I}^{2}=88 \%$ ). Four studies $^{3,9,19,22}$ provided data for length of hospital stay, and results showed that DEX shortened hospital stays (MD, 0.50 days; $95 \% \mathrm{CI},-0.97$ to $-0.03 ; P=0.04 ; \mathrm{I}^{2}=56 \%$ ). Only the study by Huang et al..$^{15}$ reported median duration of MV between the DEX (21.0 hr; 95\% CI, 18.6 to 21.4) and control (28.0 hr; 95\% CI, 25.6 to 30.4$)$ groups. Two studies compared the length of ICU stay between groups. Therefore, there were insufficient data to perform metaanalyses for duration of MV and length of ICU stay. 


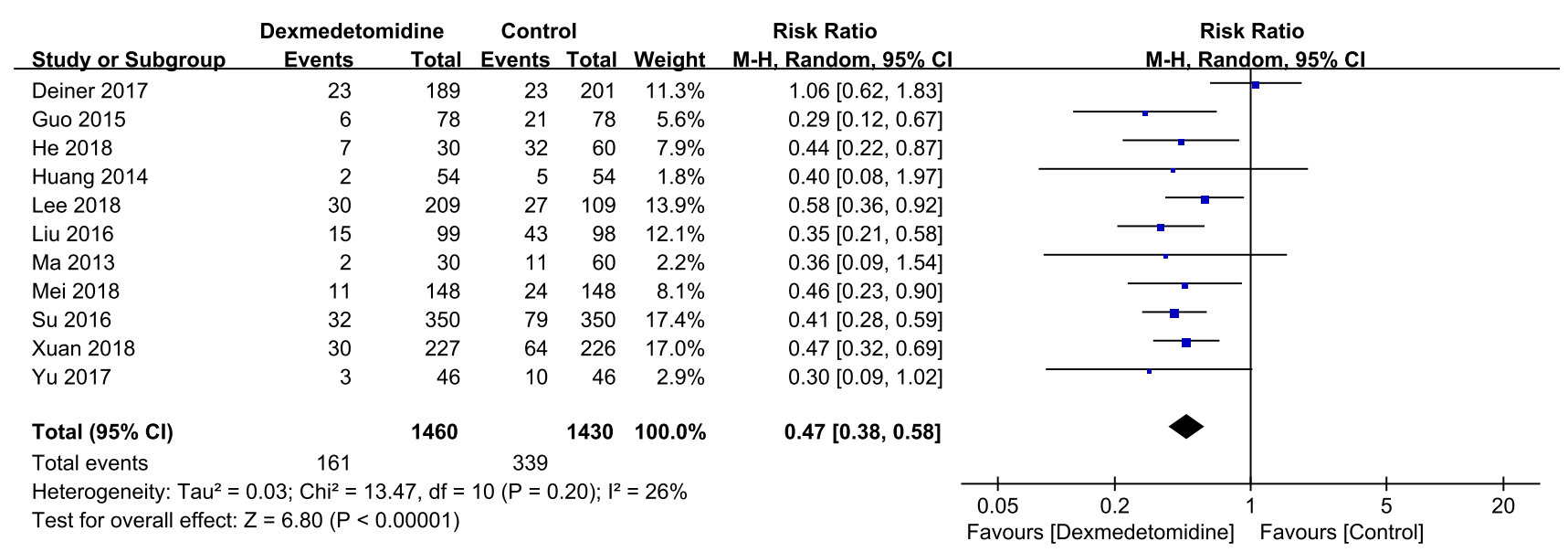

Fig. 3 Meta-analysis of the incidence of postoperative delirium after non-cardiac surgery

Publication bias

We evaluated potential publication bias of included studies using a funnel plot (Fig. 7). Egger's test showed no significant asymmetry of the funnel plot $(P=0.55)$, indicating that there was no significant publication bias.

\section{Discussion}

This was an updated meta-analysis, including 11 studies with 2,890 patients, exploring the efficacy of DEX on delirium in elderly patients after non-cardiac surgery. Our meta-analysis, based on that conducted by Duan et al., ${ }^{10}$ included an additional five studies involving 1,249 patients,

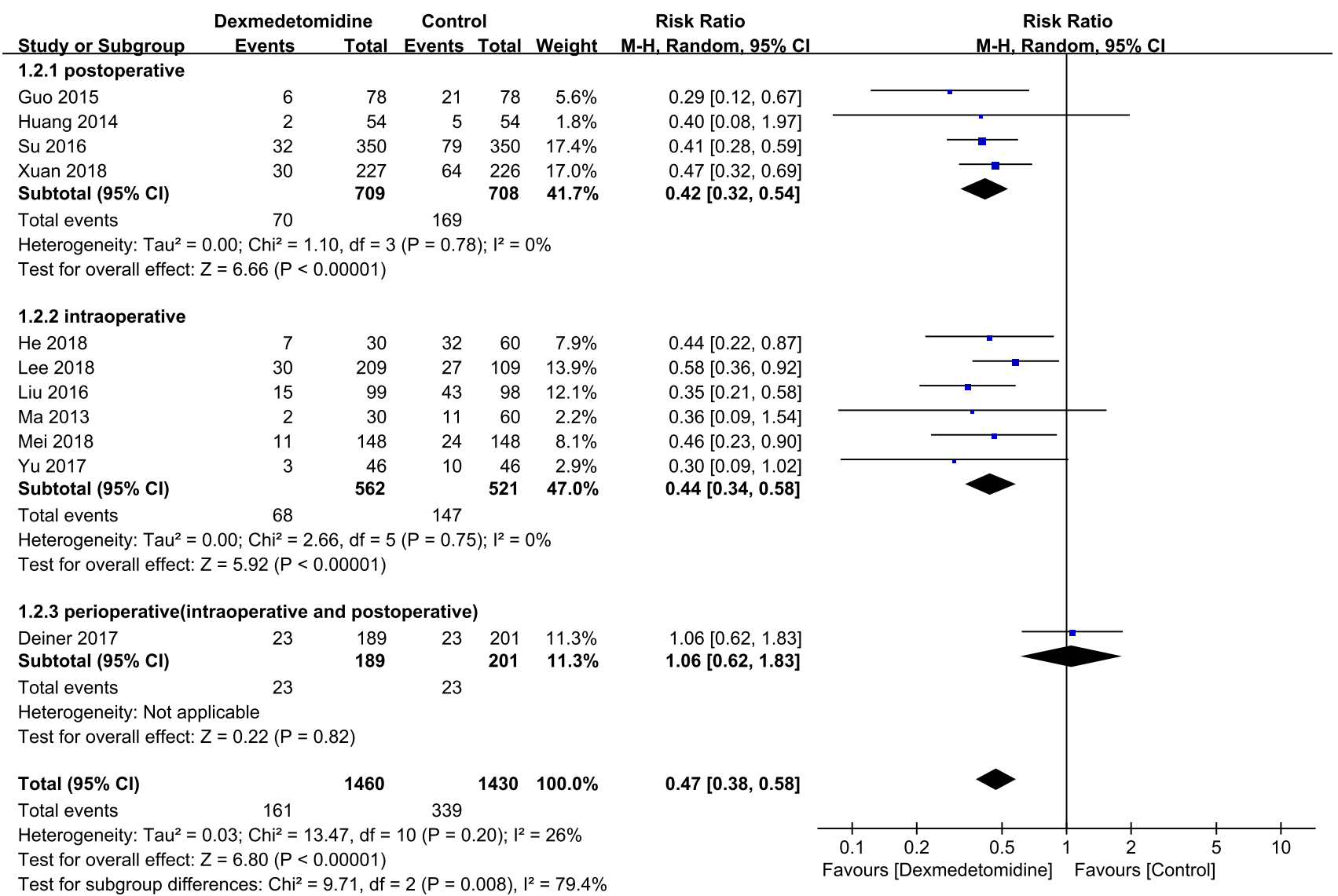

Fig. 4 Subgroup analysis of the incidence of postoperative delirium by starting time of dexmedetomidine administration (intraoperative, postoperative, or perioperative) 


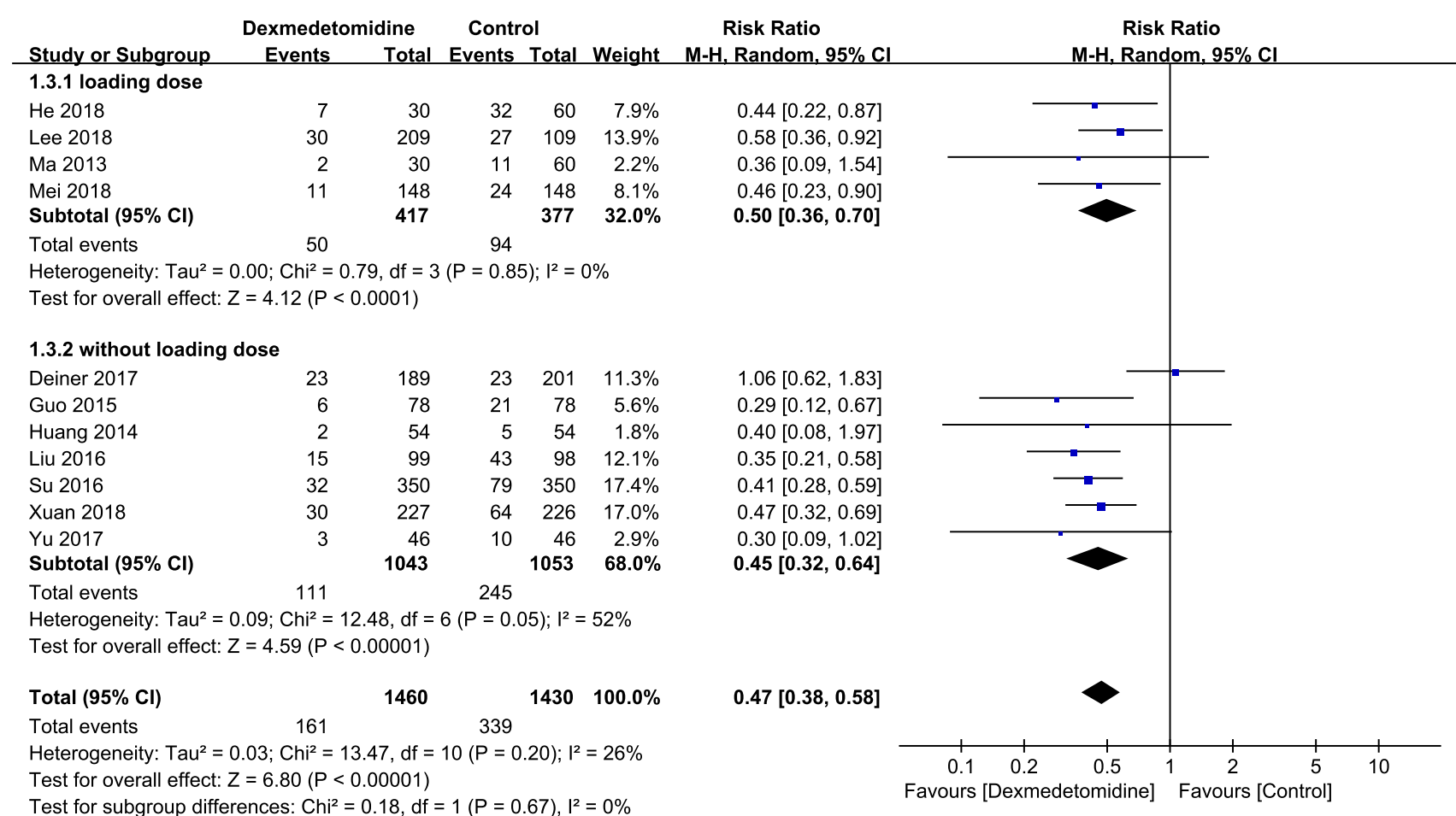

Fig. 5 Subgroup analysis of the incidence of postoperative delirium by whether a loading dose was used

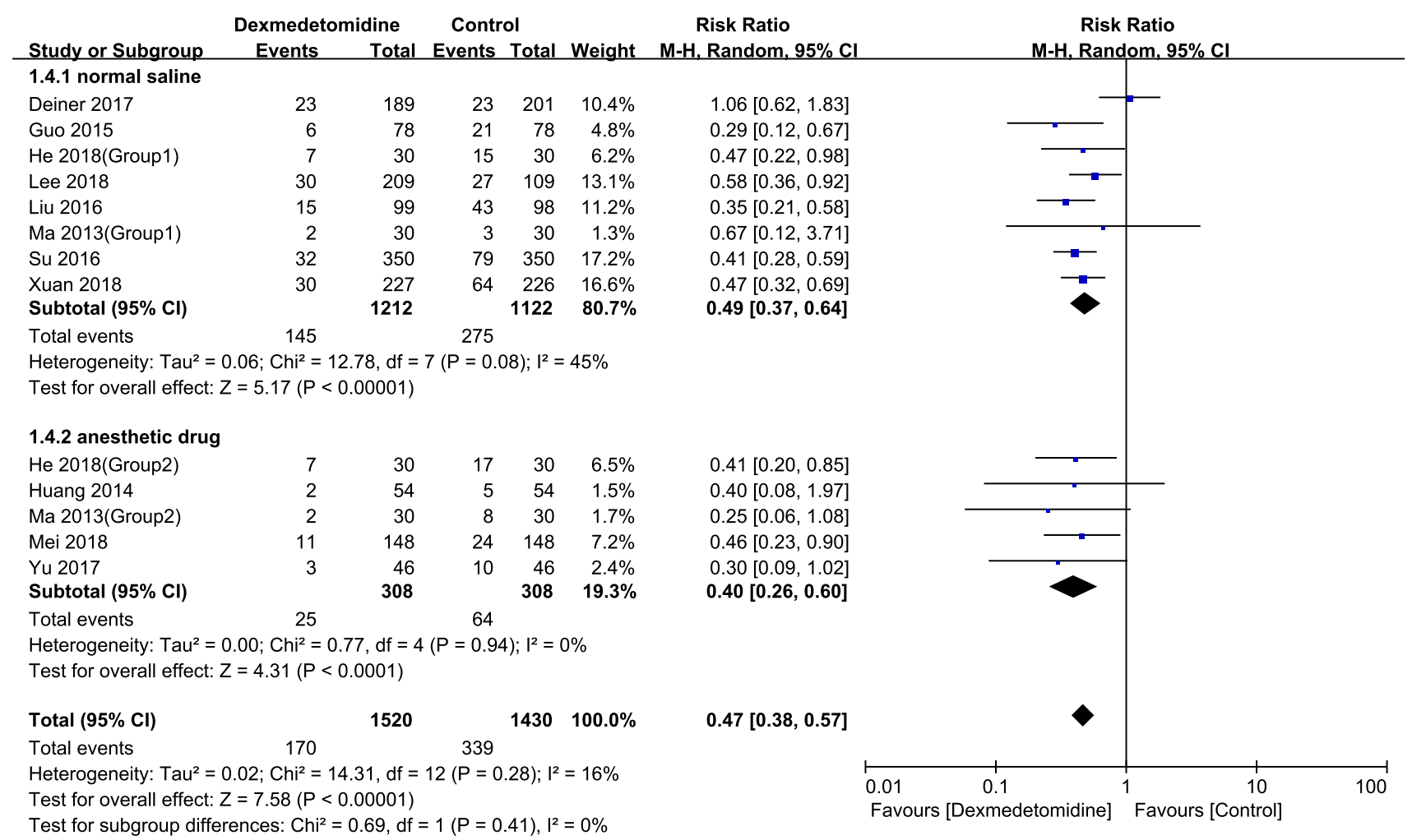

Fig. 6 Subgroup analysis of the incidence of postoperative delirium by different control drugs 
Table 3 Definitions of hypotension and bradycardia

\begin{tabular}{|c|c|c|}
\hline Studies & Hypotension & Bradycardia \\
\hline Huang $^{15}$ & $\mathrm{SBP}<80 \mathrm{mmHg} ; \mathrm{DBP}<50 \mathrm{mmHg}$; a decrease of $>30 \%$ from baseline & $<40$ beats $\cdot \min ^{-1}$; a decrease of $>30 \%$ from baseline \\
\hline Guo $^{16}$ & A decrease of $>30 \%$ from baseline & $<50$ beats $\cdot \min ^{-1}$ \\
\hline $\mathrm{Su}^{3}$ & $\mathrm{SBP}<95 \mathrm{mmHg} ;$ a decrease of $>20 \%$ from baseline & $<55$ beats $\cdot \min ^{-1}$; a decrease of $>20 \%$ from baseline \\
\hline Deiner $^{9}$ & No report & No report \\
\hline Xuan $^{22}$ & A decrease of $>20 \%$ from baseline & A decrease of $>20 \%$ from baseline \\
\hline
\end{tabular}

$\mathrm{DBP}=$ diastolic blood pressure; $\mathrm{SBP}=$ systolic blood pressure

which contributed to a more precise estimate of effect. We also performed subgroup analyses of DEX administered with or without a loading dose and of different control drugs to evaluate the efficacy of DEX on POD incidence. We found that DEX administration reduced the incidence of POD as well as the time to extubation and length of hospital stay, compared with the control group. But we also found that DEX was associated with increased risks of hypotension and bradycardia.

Delirium is a common, serious condition associated with increased morbidity and mortality in older patients. ${ }^{23}$ The multifactorial model for the etiology of delirium has been well-validated and widely accepted in elderly patients. ${ }^{24}$ Dexmedetomidine's ability to reduce POD might be associated with its specific characteristics. Dexmedetomidine has a significant opioid-sparing effect due to high and specific $\alpha_{2}$-adrenergic receptor selectivity. It also lacks clinically significant anticholinergic effects, attenuates the inflammatory response, and improves quality of sleep in critically ill patients. ${ }^{25-28}$ Moreover, at least two theories have been formulated to explain how DEX reduced POD incidence by these criteria in the study by Maldonado et $a .^{29}$ Therefore, DEX presents a potentially attractive means of preventing POD in elderly patients after non-cardiac surgery. In addition, there was no significant

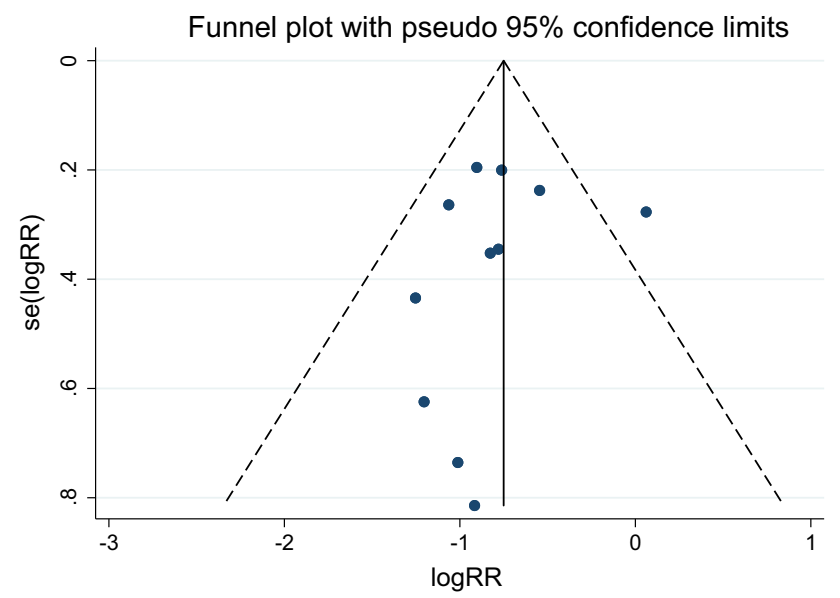

Fig. 7 Funnel plot of meta-analysis of the incidence of postoperative delirium heterogeneity among all studies in our meta-analysis $\left(\mathrm{I}^{2}=\right.$ $26 \% ; P=0.20)$. The pooled result of our meta-analysis was stable in sensitivity analyses. In addition, all of the studies in our meta-analysis used CAM or CAM-ICU to identify delirium. This method is the most widely used because of its high validity and reliability, with sensitivity of 94-100\% and $81 \%$ and specificity of $90-95 \%$ and $96 \%$, respectively. ${ }^{30,31}$ Furthermore, we included three studies $^{3,9,22}$ with large double-blinded and parallel-group RCTs in our meta-analysis, as they would have an important impact on the pooled result. Consequently, that DEX reduces the incidence of POD in elderly patients after non-cardiac surgery seems to be a reliable conclusion.

Subgroup analysis revealed that DEX administration reduced POD incidence during the intraoperative and postoperative periods. This conclusion was in accordance with the results of a recent meta-analysis of DEX's efficacy on POD. ${ }^{10}$ Our meta-analysis included more studies with elderly patients after non-cardiac surgery, and we conducted analyses of three subgroups representing the intraoperative, postoperative, and perioperative periods. Nevertheless, we included only one study in the perioperative subgroup. Further exploration is needed to clarify the effect of perioperative (intraoperative and postoperative) DEX administration on POD incidence.

We performed further subgroup analysis by whether a loading dose was used, and the result agreed with another meta-analysis that showed a decrease in POD incidence when DEX was administered with or without a loading dose. $^{32}$ Notably, the studies in the DEX-without-loadingdose subgroup were accompanied by significant heterogeneity $\left(\mathrm{I}^{2}=52 \% ; P=0.05\right)$, so the result was uncertain. One study in this subgroup, that by Deiner et al., was considered an important source of heterogeneity. This study restricted DEX administration to the intraoperative period and two subsequent hours, rather than infusing it over a prolonged postoperative period. This duration of administration was relatively shorter than those in the other four studies $3,15,16,22$ in which DEX was administered postoperatively. The DEX infusion rate differed in every study we included. In the study by Deiner et al., ${ }^{9}$ DEX was administered at a constant dose of $0.5 \mu \mathrm{g} \cdot \mathrm{kg}^{-1} \cdot \mathrm{hr}^{-1}$ for all participants, but in other studies it 
was infused at different doses: $0.1 \mu \mathrm{g} \cdot \mathrm{kg}^{-1} \cdot \mathrm{hr}^{-1,3,22} 0.2-$ $0.7 \mu \mathrm{g} \cdot \mathrm{kg}^{-1} \cdot \mathrm{hr}^{-1},{ }^{15,18} 0.2 \mu \mathrm{g} \cdot \mathrm{kg}^{-1} \cdot \mathrm{hr}^{-116}$ and $0.2-0.4$ $\mu \mathrm{g} \cdot \mathrm{kg}^{-1} \cdot \mathrm{hr}^{-1} \cdot{ }^{17}$ In addition, anesthesia depth was not monitored, ${ }^{9}$ leading to potentially deeper anesthesia, whereas BIS monitoring was performed in three other studies. ${ }^{16,17,22}$ Furthermore, a large proportion of patients in this study had presurgical cognitive impairment (63\%). ${ }^{9}$ Deiner et al. used the CAM-ICU instrument in the postanesthesia care unit to assess delirium, meaning that the detection rate for delirium was limited. Also, this study ${ }^{9}$ was conducted in the U.S., so the characteristics of its participants might differ from those of patients in the studies conducted in China. ${ }^{3,15-18,22}$ Because of all these factors, Deiner et al. drew the opposite conclusion from the other studies. In addition, three studies ${ }^{15,16,18}$ were assessed as having unclear risk of selection, performance, and detection bias, while four others ${ }^{3,9,17,22}$ were evaluated as having low risk of bias. The types of surgery that patients underwent differed among these studies in this subgroup, and so they also might contribute to this heterogeneity.

Additionally, subgroup analysis for different control drugs (NS or anesthetic drugs) revealed that the DEX group had a significant decrease in POD incidence compared with the control group. Dexmedetomidine is thought to have intrinsic delirium-reducing properties, based on its multiple characteristics. ${ }^{29}$ Also, propofol, midazolam, and morphine have been shown to increase the risk of POD. ${ }^{25}$ Previous studies have similarly revealed that DEX was associated with reduced POD incidence when compared with anesthetic drugs or NS. ${ }^{29,32}$ The study by Deiner et $a l{ }^{9}{ }^{9}$ contributed heterogeneity here as well, mild in this case $\left(\mathrm{I}^{2}=45 \% ; P=0.08\right)$ for the NS subgroup. Therefore, more high-quality studies with large sample size are needed to confirm this result.

The most commonly reported adverse events of DEX are hypotension and bradycardia, which are associated with an $\boldsymbol{\alpha}_{2}$ adrenoreceptor agonist mechanism. ${ }^{33,34}$ It was not surprising that the incidences of hypotension and bradycardia were higher in the DEX group in our metaanalysis. In addition, we found that DEX shortened the time to extubation and the length of hospital stay. Conversely, one meta-analysis ${ }^{32}$ found no significant difference in length of hospital stay between DEX and control groups. Nevertheless, there were limited data and substantial heterogeneity among studies, which would contribute to unreliability of our pooled results.

There are several overall limitations to our metaanalysis. First, the sample sizes of some studies included in our meta-analysis are small, so there is a high risk of overestimating treatment effects. Second, some excluded studies might have reported adverse events and important clinical results; therefore, we could not acquire complete data to perform the meta-analysis of adverse events and some clinical results. Third, surgery types and DEX regimens vary widely among the included studies. These variables might have produced the clinical heterogeneity that influenced the results, but unfortunately such variables could not be excluded. Fourth, the majority of non-cardiac surgical patients in the included studies did not routinely require postoperative ICU care or long-term maintenance of MV. Current guidelines suggest sedation with DEX for a relatively long time in adult ICU patients on MV. ${ }^{35}$ The patients in four studies $3,15,16,22$ admitted to the ICU received DEX for at least $12 \mathrm{hr}$. Nevertheless, Deiner et al. infused DEX for only two hours in the postanesthesia care unit. Thus, the validity and generalizability of DEX in non-ICU patients that was not explored in our metaanalysis should be further evaluated. Finally, the maintenance dose $\left(0.2-0.7 \mu \mathrm{g} \cdot \mathrm{kg}^{-1} \cdot \mathrm{hr}^{-1}\right)$ in some studies was not fixed and may have been titrated based on hemodynamic changes or sedative scores, while in other studies the rate of infusion was maintained by fixed dose $\left(0.1,0.2,0.4\right.$ or $\left.0.5 \mu \mathrm{g} \cdot \mathrm{kg}^{-1} \cdot \mathrm{hr}^{-1}\right)$. Because the dose of DEX varied in these studies, we could not draw from them an accurate conclusion about what dose would be optimal.

\section{Conclusion}

In summary, the administration of dexmedetomidine during the intraoperative or postoperative periods reduces the incidence of POD in elderly patients after non-cardiac surgery, but this benefit comes at the cost of an increased incidence of hypotension and bradycardia. Further high-quality large randomized clinical trials are needed both to confirm the validity of our results and to determine the optimal dose and timing of dexmedetomidine administration.

Acknowledgements We would like to thank Dr. Bing Wang for her assistance and LetPub (www.letpub.com) for its linguistic assistance.

Conflicts of interest None declared.

Editorial responsibility This submission was handled by Dr. Philip M. Jones, Associate Editor, Canadian Journal of Anesthesia.

Author contributions Hao Pan contributed to all aspects of this manuscript, including study conception and design, literature search, acquisition, analysis and interpretation of data, quality assessment of studies, and drafting and revising the manuscript. Mengyuan Zhang contributed to the study conception and design, literature search, acquisition, analysis and interpretation of data, quality assessment of studies, and drafting the manuscript. Yan Wang was involved in the literature search, acquisition, analysis and interpretation of data, and revising the manuscript. Chengxiao Liu, Xiaochun Ma and Yanbing $X u$ were involved in analysis and interpretation of data, drafting the manuscript and revising it for important intellectual content.

Financial support and sponsorship None. 


\section{References}

1. Inouye SK. Delirium in older persons. N Engl J Med 2006; 354: 1157-65.

2. Inouye $S K$, Westendorp $R G$, Saczynski JS. Delirium in elderly people. Lancet 2014; 383: 911-22.

3. Su X, Meng ZT, Wu XH, et al. Dexmedetomidine for prevention of delirium in elderly patients after non-cardiac surgery: a randomised, double-blind, placebo-controlled trial. Lancet 2016; 388: 1893-902.

4. Mazzola P, Bellelli G, Broggini V, et al. Postoperative delirium and pre-fracture disability predict 6-month mortality among the oldest old hip fracture patients. Aging Clin Exp Res 2015; 27: 5360.

5. Hshieh T, Yue J, Oh E, et al. Effectiveness of multicomponent nonpharmacological delirium interventions: a meta-analysis. JAMA Intern Med 2015; 175: 512-20.

6. Mo $Y$, Zimmermann AE. Role of dexmedetomidine for the prevention and treatment of delirium in intensive care unit patients. Ann Pharmacother 2013; 47: 869-76.

7. Djaiani $G$, Silverton N, Fedorko L, et al. Dexmedetomidine versus propofol sedation reduces delirium after cardiac surgery: a randomized controlled trial. Anesthesiology 2016; 124: 362-8.

8. Liu X, Xie $G$, Zhang $K$, et al. Dexmedetomidine vs propofol sedation reduces delirium in patients after cardiac surgery: a meta-analysis with trial sequential analysis of randomized controlled trials. J Crit Care 2017; 38: 190-6.

9. Deiner $S$, Luo $X$, Lin $H M$, et al. Intraoperative infusion of dexmedetomidine for prevention of postoperative delirium and cognitive dysfunction in elderly patients undergoing major elective noncardiac surgery: a randomized clinical trial. JAMA Surg 2017; 152: e171505.

10. Duan X, Covurn M, Rossaint R, Sanders RD, Waesberghe JV, Kowark A. Efficacy of perioperative dexmedetomidine on postoperative delirium: systematic review and meta-analysis with trial sequential analysis of randomized controlled trials. $\mathrm{Br}$ J Anaesth 2018; 121: 384-97.

11. Flükiger J, Hollinger A, Speich B, et al. Dexmedetomidine in prevention and treatment of postoperative and intensive care unit delirium: a systematic review and meta-analysis. Ann Intensive Care 2018; 8: 92.

12. Liberati A, Altman DG, Tetzlaff $J$, et al. The PRISMA statement for reporting systematic reviews and meta-analyses of studies that evaluate healthcare interventions: explanation and elaboration. BMJ 2009; 339: b2700.

13. Higgins JP, Altman DG, Gotzsche PC, et al. The Cochrane Collaboration's tool for assessing risk of bias in randomized trials. BMJ 2011; 343: d5928.

14. Ma PP, Piao MH, Wang YS, Ma HC, Feng CS. Influence of dexmedetomidine and sub-anesthetic dose of ketamine on postoperative delirium in elderly orthopedic patients under total intravenous anesthesia. J Jilin Univ (Med Ed) 2013; 39: 128-32.

15. Huang $F$, Wang $J$, Yang $X$, et al. Sedative effects of dexmedetomidine in postoperative elder patients on mechanical ventilation (Chinese). Zhonghua Yi Xue Za Zhi 2014; 94: 3211-5.

16. Guo Y, Sun LL, Chen ZF, Li QF, Jiang $H$. Preventive effect of dexmedetomidine on postoperative delirium in elderly patients with oral cancer (Chinese). Shanghai Kou Qiang Yi Yue 2015; 24: 236-9.

17. Liu Y, Ma L, Gao M, Guo W, Ma Y. Dexmedetomidine reduces postoperative delirium after joint replacement in elderly patients with mild cognitive impairment. Aging Clin Exp Res 2016; 28: 729-36.
18. Yu DN, Zhu Y, Ma J, Sun $Q$. Comparison of post-anesthesia delirium in elderly patients treated with dexmedetomidine and midazolam maleate after thoracic surgery. Biomed Res 2017; 28: 6852-5.

19. Mei B, Meng $G, X u G$, et al. Intraoperative sedation with dexmedetomidine is superior to propofol for elderly patients undergoing hip arthroplasty: a prospective randomized controlled study. Clin J Pain 2018; 34: 811-7.

20. Lee C, Lee CH, Lee G, Lee M, Hwang J. The effect of the timing and dose of dexmedetomidine on postoperative delirium in elderly patients after laparoscopic major non-cardiac surgery: a double blind randomized controlled study. J Clin Anesth 2018; 47: 27-32.

21. He F, Shen L, Zhong J. A study of dexmedetomidine in the prevention of postoperative delirium in elderly patients after vertebral osteotomy. Int J Clin Exp Med 2018; 11: 4984-90.

22. Xuan $Y$, Fan R, Chen J, et al. Effects of dexmedetomidine for postoperative delirium after joint replacement in elderly patients: a randomized, double-blind, and placebo-controlled trial. Int $\mathrm{J}$ Clin Exp Med 2018; 11: 13147-57.

23. Oh ES, Fong TG, Hshieh TT, Inouye SK. Delirium in older persons: advances in diagnosis and treatment. JAMA 2017; 318: 1161-74.

24. Inouye SK, Charpentier PA. Precipitating factors for delirium in hospitalized elderly persons. Predictive model and interrelationship with baseline vulnerability. JAMA 1996; 275: 852-7.

25. Reade $M C$, Finfer $S$. Sedation and delirium in the intensive care unit. N Engl J Med 2014; 370: 444-54.

26. Pandharipande P, Ely EW, Maze M. Alpha-2 agonists: can they modify the outcomes in the postanesthesia care unit? Curr Drug Targets 2005; 6: 749-54.

27. Alexopoulou $C$, Kondili E, Diamantaki E, et al. Effects of dexmedetomidine on sleep quality in critically ill patients: a pilot study. Anesthesiology 2014; 121: 801-7.

28. Ueki M, Kawasaki T, Habe K, Hamada K, Kawasaki C, Sata T. The effects of dexmedetomidine on inflammatory mediators after cardiopulmonary bypass. Anesthesia 2014; 69: 693-700.

29. Maldonado JR, Wysong A, van der Starre PJ, Block T, Miller $C$, Reitz BA. Dexmedetomidine and the reduction of postoperative delirium after cardiac surgery. Psychosomatics 2009; 50: 206-17.

30. Wei LA, Fearing MA, Sternberg EJ, Inouye SK. The Confusion Assessment Method: a systematic review of current usage. J Am Geriatr Soc 2008; 56: 823-30.

31. Luetz A, Heymann A, Radtke FM, et al. Different assessment tools for intensive care unit delirium: which score to use? Crit Care Med 2010; 38: 409-18.

32. Wu M, Liang $Y$, Dai Z, Wang S. Perioperative dexmedetomidine reduces delirium after cardiac surgery: a meta-analysis of randomized controlled trials. J Clin Anesth 2018; 50: 33-42.

33. Lin $Y Y$, He B, Chen J, Wang ZN. Can dexmedetomidine be a safe and efficacious sedative agent in post-cardiac surgery patients? A meta-analysis. Crit Care 2012; 16: R169.

34. Kamibayashi T, Maze M. Clinical uses of alpha2-adrenergic agonists. Anesthesiology 2000; 93: 1345-9.

35. Barr J, Fraser GL, Puntillo K, et al. Clinical practice guidelines for the management of pain, agitation, and delirium in adult patients in the intensive care unit. Crit Care Med 2013; 41: $263-$ 306.

Publisher's Note Springer Nature remains neutral with regard to jurisdictional claims in published maps and institutional affiliations. 